\title{
Safety system for child pillion riders of underbone motorcycles in Malaysia
}

\begin{abstract}
Objective: Motorcycles are a common mode of transport for most Malaysians. Underbone motorcycles are one of the most common types of motorcycle used in Malaysia due to their affordable price and ease of use, especially in heavy traffic in the major cities. In Malaysia, it is common to see a young or child pillion rider clinging on to an adult at the front of the motorcycle. One of the main issues facing young pillion riders is that their safety is often not taken into account when they are riding on a motorcycle. This article reviews the legally available systems in child safety for underbone motorcycles in Malaysia while putting forth the need for a safety system for child pillion riders. Method: Various databases were searched for underbone motorcycle safety systems, related legislation, motorcycle accident data, and types of injuries and these were reviewed to put forth the need for a new safety system. Results: In motorcycle-related accidents, children usually sustain lower limb injuries, which could temporarily or permanently inhibit the child's movements. Accident statistics in Malaysia, especially those involving motorcycles, reflect a pressing need for a reduction in the number of accidents. In Malaysia, the legislation does not go beyond the mandatory use of safety helmets for young pillion users. There is a pressing need for another safety system or mechanism(s) for young pillion riders of underbone motorcycles. Enforcement of laws to enforce the usage of passive safety systems such as helmets and protective gear is difficult in underdeveloped and developing countries. Conclusion: The intervention of new technology is inevitable. Therefore, this article highlights the need for a new safety backrest system for child pillion riders to ensure their safety.
\end{abstract}

Keyword: Backrest; Pillion; Children; Safety; Motorcycle 